\title{
TITLE: Allergic gastroenteritis hospital admission time trends in Australia and New Zealand 1998-2016
}

\section{ORIGINAL ARTICLE}

Version 12 July 2017

\section{AUTHORS}

* Raymond James Mullins (1,2)

Consultant Physician, Clinical Immunology and Allergy

Qualifications: MB BS, PhD, FRACP, FRCPA

(1) Suite 1, John James Medical Centre

175 Strickland Crescent, Deakin ACT 2600, Australia

(2) Senior Clinical Lecturer, Medical School, Australian National University

Canberra, ACT 0200, Australia

Tel +61-2-6282 2568; Fax +61-2-6282 2526

Email: raymond.mullins@gmail.com

* Corresponding author

Paul J. Turner $(3,4,5)$

Clinician Scientist and Consultant in Paediatric Allergy \& Immunology

Qualifications: BM BCh, FRACP, PhD

(3) Section of Paediatrics, Imperial College London, London, UK

(4) Immunisation, Hepatitis and Blood Safety Department, Public Health England, London, UK

(5) Discipline of Child and Adolescent Health, University of Sydney, Sydney, Australia 
Email: p.turner@imperial.ac.uk

\section{Elizabeth H Barnes (6)}

Biostatistician

Qualifications: BAppSc, MStat

(6) NHMRC Clinical Trials Centre, University of Sydney NSW 2006

Email: Liz.Barnes@ctc.usyd.edu.au

\section{Dianne E Campbell $(5,7)$}

Consultant Paediatric Physician, Clinical Immunology and Allergy

Qualifications: MB BS, PhD, FRACP

(5) Discipline of Child and Adolescent Health, University of Sydney, NSW, Australia

(7) Children's Hospital at Westmead, Sydney, Australia

Email: dianne.campbell1@health.nsw.gov.au 
1 TITLE: Allergic gastroenteritis hospital admission time trends in Australia

2 and New Zealand $1998-2016$

3

4 Version $1 \underline{6}$ August 2017

5

6 KEYWORDS

$7 \quad$ Allergic gastroenteritis; anaphylaxis; epidemiology; food allergy.

8

9 ABBREVIATIONS

10 AG Allergic gastroenteritis

11 FA Food allergy

12 FPIES Food protein induced enterocolitis syndrome

13

14 Article contents

15 Word count $\quad 785$

16 Tables 1

17 Figures 1

18 References 8

19

$20 \quad$ Funding

$21 \quad$ Nil

22

23 Conflicts of Interest

24 The authors report no conflicts of interest.

25 


\section{ABSTRACT}

28 Aim

29 Recent epidemiological studies indicate increases in hospital food allergy-related 30 anaphylaxis admission rates in Australian and New Zealand. The aim of the study

31 was to examine whether non-IgE mediated food allergy might have increased in 32 parallel.

\section{Methods}

34 We analysed childhood hospital admissions rates by ICD 10 codes for allergic 35 gastroenteritis (AG) and infective gastroenteritis in Australia and New Zealand 36 between June 1998 and July 2014.

\section{$37 \quad$ Results}

38 In Australia most AG-related admissions (73\%) occurred in those aged <1 year 39 and increased by $7.3 \%$ year $\left(95 \%\right.$ CI 5.5-9.3, $\mathrm{P}<0.0001$ ) from 6.8 to $26.5 / 10^{5}$ 40 population. Similar trends were observed for New Zealand; 81\% of admissions 41 occurred in those aged $<1$ year and increased by $9.4 \%$ year (95\% CI 5.5-9.3, $42 \quad \mathrm{P}<0.0001$ ) from 7.2 to $30.7 / 10^{5}$ population. By contrast there were no significant 43 changes in AG-related admission rates in the older patients and infective 44 gastroenteritis admissions fell in both countries in those aged $<1$ year; Australia 45 by $4.4 \% /$ year $(95 \%$ CI $4.3-4.6, \mathrm{P}<0.0001)$ and in New Zealand by $5.8 \% /$ year $46 \quad$ (95\%CI 5.4-6.2, $\mathrm{P}<0.0001)$. 
48

\section{Conclusions}

49 We observed a four-fold increase in AG-related admission rates in two countries

50 with known high rates of IgE-mediated food allergy/anaphylaxis. If confirmed by

51 other studies, it will be of interest to determine if factors thought to contribute to

52 the increase in IgE-mediated $\mathrm{FA}^{8}$ might also play a role in non-IgE mediated

53 gastroenterological FA syndromes.

54

55

56 What is known on this topic

57 - IgE-mediated childhood food allergy has increased over the last 20 years in $58 \quad$ Australia and New Zealand.

59

- It is unknown whether non-IgE-mediated food allergy has increased as well.

60

61 What this paper adds

62

- Hospital admissions for allergic gastroenteritis (but not infective

63 gastroenteritis) increased four-fold between 1998 and 2014.

64 - If this represents a true increase (and not greater recognition), it remains

65 uncertain whether the same risk factors for IgE-mediated food allergy are

66 relevant for non-IgE-mediated food allergy. 
67

68

69

70

71

72

73

74

75

76

77

78

79

80

81

82

83

84

85

86

87

88

89

90

91

\section{Introduction}

Epidemiogical data (e.g. hospitalization rates) indicate that IgE-mediated food allergy (FA) and anaphylaxis has increased over the past 2 decades ${ }^{1,2}$. With the possible exception of eosinophilic esophagitis ${ }^{3}$ and coeliac disease, it is unclear whether other non-IgE mediated FA may have increased as well. "Allergic gastroenteritis" (AG) as classified under the International Statistical Classification of Diseases (ICD-10) encompasses a number of non-IgE mediated allergic conditions, including food protein-induced enterocolitis syndrome (FPIES), eosinophilic enteritis and colitis, food protein-induced enteropathy, "other allergic dietetic gastroenteritis and colitis", food hypersensitivity enteritis and colitis (but specifically not eosinophilic oesophagitis or coeliac disease). We sought to determine whether AG-related paediatric hospital admission rates have increased in parallel with increases in food-related IgE-mediated anaphylaxis in Australia and New Zealand

\section{Methodology}

We obtained ICD-10 classified hospital admissions data, as collected by the Australian Institute of Health and Welfare and the New Zealand Ministry of Health. Hospital admissions between July 1998 (Australia) or July 2000 (New Zealand) to June 2014 attributed to AG (K52.2) were examined. Infective gastroenteritis admissions (A0 to A9) and all cause admissions (available for Australia only) were examined as comparators to control for any trend for overall increased hospitalisation for gastrointestinal disorders that may have confounded analysis. Age ranges of $<1$ year, 1-4 years and 5-14 years were selected to facilitate comparison with other admissions-related studies ${ }^{2}$. More 
92 detailed codes for FPIES (K52.21), food protein-induced enteropathy (K52.22) or 93 the term "other allergic dietetic gastroenteritis and colitis" (K52.29) were 94 unavailable from the institutions providing data (AIHW, NZ MoH). Data are 95 expressed as rates $/ 10^{5}$ population using concurrent national population data 2 . 96 Time trends were analyzed using Poisson regression with year as a continuous 97 predictor and total population as exposure variable. Analysis was performed 98 using SAS 9.3 statistical software. The Human Research and Ethics committee of 99 Calvary Bruce/Calvary John James Private Hospitals, Canberra, Australia 100 approved the study.

101

102

\section{Results}

103 Hospital admissions for AG increased over the study period in Australia and New 104 Zealand. In Australia most AG-related admissions (73\%) occurred in those aged 105 < < year with slight male predominance (58\%) and increased by 7.3\%/year 106 (95\%CI 5.5-9.3, $\mathrm{P}<0.0001$ ) from 6.8 to $26.5 / 10^{5}$ population (Table 1, Figure $1 \mathrm{~A}$ ).

107 Similar trends were observed in New Zealand AG-related admissions; 81\% 108 occurred in those aged <1 year with slight male predominance (59\%) and 109 increased by $9.4 \%$ year $(95 \% \mathrm{CI} 5.5-9.3, \mathrm{P}<0.0001)$ from 7.2 to $30.7 / 10^{5}$

110 population (Figure 1B). By contrast there were no significant changes in AG111 related admission rates in the two older age groups in either country (Table 1).

112 When infective gastroenteritis admissions were examined as comparators, these 113 decreased in Australia by 4.4\%/year (95\%CI 4.3-4.6, $\mathrm{P}<0.0001$ ) and in New 114 Zealand by 5.8\%/year (95\%CI 5.4-6.2, P<0.0001) in those aged $<1$ year. In 
115 Australia there was a minor decrease in all-cause admissions of $0.1 \%$ /year

116 (95\%CI 0-0.1, P=0.0001).

117 Discussion

118 We report a 4-fold increase in AG-related hospital admission rates for AG in 119 Australia and New Zealand in infants aged <1 year between 1998/99 and 120 2013/14. These trends (with slight male predominance and very similar rates 121 between the two countries) could not be explained by increases in overall 122 hospitalization rates, or consistent changes in admission rates for potentially 123 mimicking conditions such as infective gastroenteritis admissionsadmissions, 124 which decreased over the period of observation (likely related to update of 125 rotavirus immunization). AG-related admissions were almost absent in older

126 Australasian age groups.

128 Many epidemiological studies rely upon ICD coding to track changes in rates of 129 disease, or changes of distribution and burden of diseases within populations. In 130 addition to the many potential caveats involved in using coding data of this 131 nature ${ }^{3}$ there are as yet unresolved questions about exactly what the K52.2 ICD 132 code represents in practice and how coders are interpreting admissions data to 133 make this decision about the admission. Accurate coding also relies upon the 134 diagnostic expertise of the health professionals making the diagnosis during the 135 hospital admission. The code is designed to identify food protein-induced 136 enterocolitis syndrome (FPIES), eosinophilic enteritis and colitis, food protein137 induced enteropathy, food hypersensitivity enteritis and colitis but specifically 138 not eosinophilic oesophagitis or coeliac disease._While it would have been 
139 informative to examine more detailed disease specific codes, such data is not 140 available for Australia or New Zealand at this time.

141

142 Overall, our data suggest a possible increase in non-IgE-mediated FA related 143 disorders such as has been already reported with eosinophilic esophagitis 144 diagnostic rates ${ }^{3}$ and is consistent with reports of increasing FPIES presentations 145 to large allergy referral centres in Australia ${ }^{4}$ and Italy ${ }^{5}$ although not the USA ${ }^{6}$. 146 While it is interesting to speculate that the increases in infant AG admissions 147 might represent FPIES, with increases in infants presenting with the profuse 148 vomiting, pallor and hypotension characteristic of FPIES requiring admission 149 (rather than emergency department assessment and discharge), such 150 conclusions are precluded by the limitations of coding data and thus inability to 151 differentiate from other related conditions (eg. food induced enteropathy with 152 failure to thrive) or mimicking conditions (infective gastroenteritis). The 153 observation that rates of admission for $A G$ in both countries for the $<1$ year age 154 group were very similar is supportive of the possibility that the majority of these 155 cases represent FPIES. If the increase in AG is confirmed by other studies, and 156 not an solely an artefact of improved recognition of disorders such as FPIES ${ }^{7}$ and 157 coding, it will be of interest to determine if factors thought to contribute to the 158 increase in IgE-mediated $\mathrm{FA}^{8}$ might also play a role in non-IgE mediated 159 gastroenterological FA syndromes.

160

161 Acknowledgments 
162 We wish to thank Chris Lewis at the New Zealand Ministry of Health for supply of 163 New Zealand Health data. PJT is in receipt of a Clinician Scientist award funded 164 by the UK Medical Research Council (reference MR/K010468/1). 
165

166

167

168

169

170

171

172

173

174

175

176

177

178

179

180

181

182

183

184

185

186

187

188

189

\section{REFERENCES}

1. Tang MLK, Mullins RJ. Clinical perspectives. Food Allergy: is prevalence increasing? Intern Med J 2017; 47 (3): 256-261. doi:10.1111/imj.13362

2. Mullins RJ, Dear KB, Tang ML. Time trends in Australian hospital anaphylaxis admissions in 1998-1999 to 2011-2012. J Allergy Clin Immunol. 2015;136(2):367-75. doi: 10.1016/j.jaci.2015.05.009

3. Dellon ES, Erichsen R, Baron JA, Shaheen NJ, Vyberg M, Sorensen HT, Pedersen L. The increasing incidence and prevalence of eosinophilic oesophagitis outpaces changes in endoscopic and biopsy practice: national population-based estimates from Denmark. Aliment Pharmacol Ther. 2015; 41(7): 662-70. doi: 10.1111/apt.13129

4. Mehr S, Kakakios A, Frith K, Kemp AS. Food protein-induced enterocolitis syndrome: 16-year experience. Pediatrics 2009; 123: e459-e464. doi: 10.1542/peds.2008-2029.

5. Sopo SM, Giorgio V, Dello Iacono I, et al. A multicentre retrospective study of 66 Italian children with food protein-induced enterocolitis syndrome: different management for different phenotypes. Clin Exp Allergy 2012; 42:1257-1265. doi: 10.1111/j.1365-2222.2012.04027.x

6. Ruffner M, Ruymann K, Barni S, et al. Food Protein-induced enterocolitis syndrome: insights from review of a large referral population. J Allergy Clin Immunol Pract 2013; 1:343-349. doi: 10.1016/j.jaip.2013.05.011.

7. Fiocchi A, Claps A, Dahdah L, Brindisi G, Dionisi-Vici C, Martelli A. Differential diagnosis of food protein-induced enterocolitis syndrome Curr Opin Allergy Clin Immunol. 2014; 14: 246-54. doi: 10.1097/ACI.0000000000000057. 
190 8. Wood RA. Advances in food allergy in 2015. J Allergy Clin Immunol. 2016;

191 138: 1541-1547. doi: 10.1016/j.jaci.2016.10.002. 
192 TABLE 1 LEGEND

193 Time trends in hospital admissions rates for allergic gastroenteritis and infective

194 gastroenteritis

195

196 FIGURE LEGENDS

197 Figure 1

198 Allergic gastroenteritis admissions in children aged less than 1 year

199 Admission rates are shown for (a) Australia and (b) New Zealand with trends

200 lines (black lines) and 95\% CI (grey lines). 


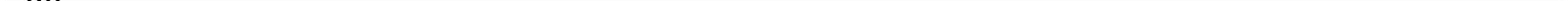


TABLE 1

\begin{tabular}{|c|c|c|c|c|c|c|c|}
\hline Condition & No. & $\begin{array}{c}\text { Rate/100,000 } \\
\text { 1998(Aust); 2000(NZ) }\end{array}$ & $\begin{array}{c}\text { Rate/100,000 } \\
2014 \\
\end{array}$ & $\%$ change/year & Lower Cl & Upper Cl & P value \\
\hline & & AUSTRALIA & & & & & \\
\hline \multicolumn{8}{|c|}{ Allergic gastroenteritis } \\
\hline$<1$ year & 633 & 6.8 & 26.5 & 7.3 & 5.5 & 9.3 & $<0.0001$ \\
\hline 1-4 years & 167 & 0.5 & 1.5 & 2.6 & -0.8 & 6 & 0.13 \\
\hline $5-14$ years & 62 & 0.2 & 0.1 & 5 & -0.6 & 10.9 & 0.081 \\
\hline \multicolumn{8}{|c|}{$\begin{array}{l}\text { Infectious } \\
\text { gastroenteritis }\end{array}$} \\
\hline$<1$ year & 73,132 & 2179.0 & 1243.3 & -4.4 & -4.3 & -4.6 & $<0.0001$ \\
\hline $1-4$ years & 169,926 & 1222.0 & 486.2 & -7.1 & -7 & -7.2 & $<0.0001$ \\
\hline $5-14$ years & 80518 & 171.2 & 158.7 & -1.1 & -1 & -1.3 & $<0.0001$ \\
\hline \multicolumn{8}{|c|}{ Total admissions } \\
\hline$<1$ year & $2,388,538$ & 54933.2 & 57820.2 & -0.1 & 0 & -0.1 & $<0.0001$ \\
\hline 1-4 years & $2,848,250$ & 17783.5 & 15787.5 & -0.9 & -0.9 & -1 & $<0.0001$ \\
\hline $5-14$ years & $3,784,606$ & 8622.6 & 9047.6 & 0.5 & 0.5 & 0.5 & $<0.0001$ \\
\hline & & NEW ZEALAND & & & & & \\
\hline \multicolumn{8}{|c|}{ Allergic gastroenteritis } \\
\hline$<1$ year & 104 & 7.2 & 30.7 & 9.4 & 4 & 15.1 & 0.0005 \\
\hline $1-4$ years & 22 & 0.4 & 0.4 & 1.4 & -8.6 & 12.5 & 0.79 \\
\hline $5-14$ years & 2 & 0 & 0 & -9 & -30 & 36.4 & 0.61 \\
\hline \multicolumn{8}{|c|}{$\begin{array}{c}\text { Infectious } \\
\text { gastroenteritis }\end{array}$} \\
\hline$<1$ year & 12278 & 1885.6 & 864.7 & -5.8 & -5.4 & -6.2 & $<0.0001$ \\
\hline $1-4$ years & 20320 & 829.6 & 368.5 & -6.7 & -6.4 & -7 & $<0.0001$ \\
\hline 5-14 years & 7058 & 95.5 & 55.6 & -6.4 & -5.8 & -6.9 & $<0.0001$ \\
\hline
\end{tabular}


Table 1

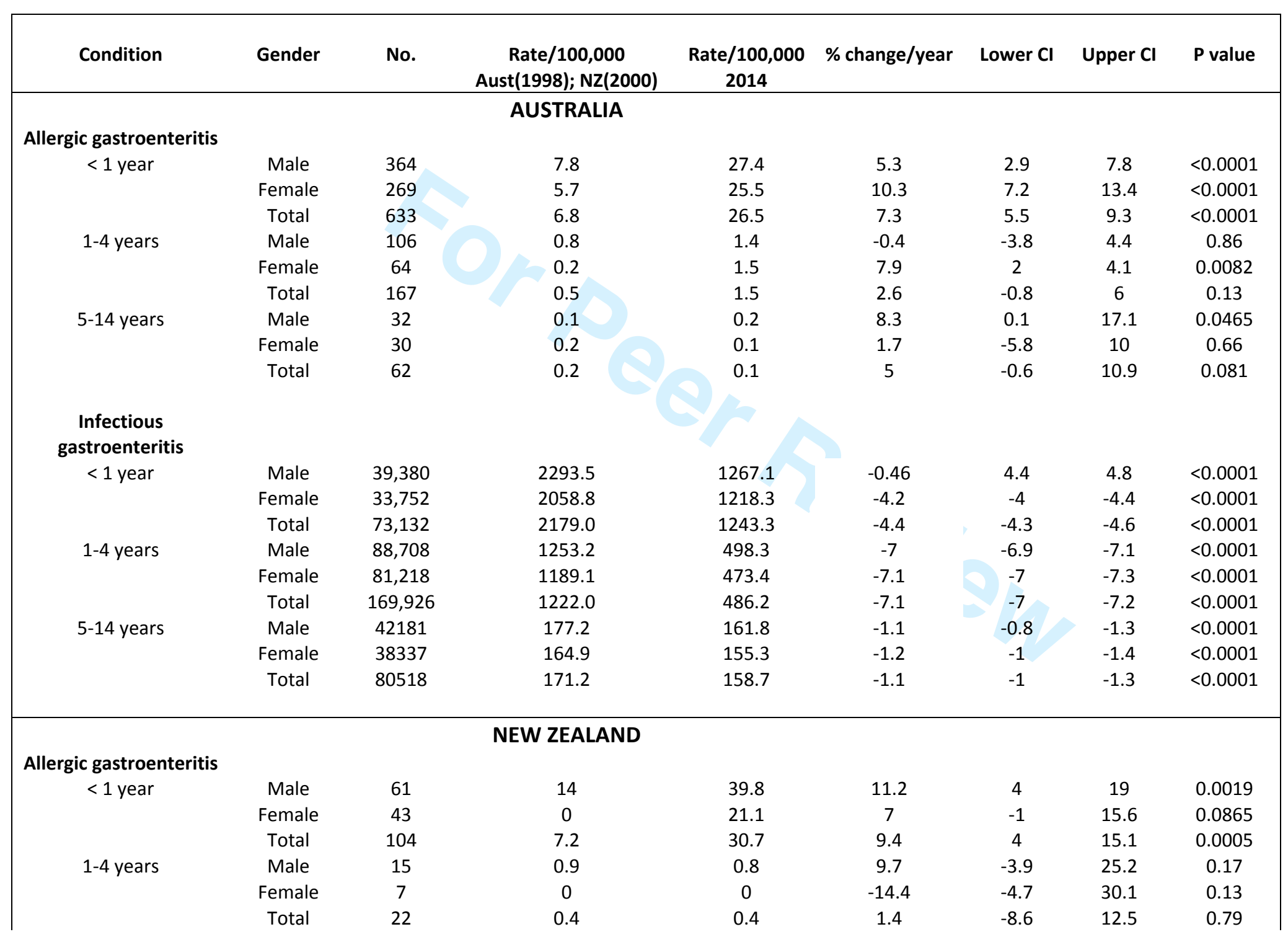




\begin{tabular}{|c|c|c|c|c|c|c|c|c|}
\hline \multirow[t]{3}{*}{$5-14$ years } & Male & 1 & 0 & 0 & -22.7 & -47 & 59.4 & 0.43 \\
\hline & Female & 1 & 0 & 0 & 3.2 & -37 & 68.2 & 0.9 \\
\hline & Total & 2 & 0 & 0 & -9 & -30 & 36.4 & 0.61 \\
\hline \multicolumn{9}{|c|}{$\begin{array}{c}\text { Infectious } \\
\text { gastroenteritis }\end{array}$} \\
\hline \multirow[t]{3}{*}{$<1$ year } & Male & 6683 & 1996.5 & 881.7 & -5.7 & -5.2 & -6.3 & $<0.0001$ \\
\hline & Female & 5595 & 1770.1 & 8482.8 & -5.9 & -5.2 & -6.5 & $<0.0001$ \\
\hline & Total & 12278 & 1885.6 & 864.7 & -5.8 & -5.4 & -6.2 & $<0.0001$ \\
\hline \multirow[t]{3}{*}{$1-4$ years } & Male & 10746 & 883.6 & 385.6 & -6.8 & -6.4 & -7.3 & $<0.0001$ \\
\hline & Female & 9574 & 772.7 & 350.5 & -6.5 & -6 & -7 & $<0.0001$ \\
\hline & Total & 20320 & 829.6 & 368.5 & -6.7 & -6.4 & -7 & $<0.0001$ \\
\hline \multirow[t]{3}{*}{$5-14$ years } & Male & 3725 & 93.2 & 59.3 & -5.8 & -5 & -6.6 & $<0.0001$ \\
\hline & Female & 3333 & 97.9 & 51.8 & -7 & -6.2 & -7.8 & $<0.0001$ \\
\hline & Total & 7058 & 95.5 & 55.6 & -6.4 & -5.8 & -6.9 & $<0.0001$ \\
\hline
\end{tabular}

